\title{
A Fault Diagnostic Method for Position Sensor of Switched Reluctance Wind Generator
}

\author{
Chao Wang ${ }^{\dagger}$, Xiao Liu*, Hui Liu* and Zhe Chen*
}

\begin{abstract}
Fast and accurate fault diagnosis of the position sensor is of great significance to ensure the reliability as well as sensor fault tolerant operation of the Switched Reluctance Wind Generator (SRWG). This paper presents a fault diagnostic scheme for a SRWG based on the residual between the estimated rotor position and the actual output of the position sensor. Extreme Learning Machine (ELM), which could build a nonlinear mapping among flux linkage, current and rotor position, is utilized to design an assembled estimator for the rotor position detection. The data for building the ELM based assembled position estimator is derived from the magnetization curves which are obtained from Finite Element Analysis (FEA) of an SRWG with the structure of 8 stator poles and 6 rotor poles. The effectiveness and accuracy of the proposed fault diagnosis method are verified by simulation at various operating conditions. The results provide a feasible theoretical and technical basis for the effective condition monitoring and predictive maintenance of SRWG.
\end{abstract}

Keywords: Extreme learning machine, Fault diagnostics, Finite element analysis, Switched reluctance generator

\section{Introduction}

With the increasing concern on the reliability and cost, Switched Reluctance Wind Generator (SRWG) has been attracting more and more attentions from the wind power academia and industry. Unlike the most commonly used Doubly Fed Induction Generator (DFIG) and Permanent Magnet Synchronous Generator (PMSG) in wind energy conversion systems, SRWG has more robust structure as there is no winding or magnet on the rotor. In addition, each phase is independent of each other in terms of structure and electromagnetism. These significant features help SRWG possess high reliability and good fault tolerant ability, making SRWG a strong candidate for the next generation variable speed wind power generators [1-8].

Although Switched Reluctance Machine (SRM) has a robust structure and high fault tolerant ability, it does not mean that it is free of fault. The relatively vulnerable parts in a SRM are stator windings, power transistors, bearings and sensors. There are a number of research works on Fault Detection and Diagnosis (FDD) of stator winding, power electronics and bearing of SRM [9-13] but very few publications concerning the FDD of position sensor [14]. Although it is a trend that the position sensor will be eliminated with the mature of sensor-less control technology [15-19], most SRGs still have position sensors in a considerable period of time. When the position sensor fails, the system should be able to detect it in the very

$\dagger$ Corresponding Author: Dept. of Energy Technology, Aalborg University, Denmark. (chw@et.aau.dk)

* Dept. of Energy Technology, Aalborg University, Denmark. ( $\{$ xil,hui,zch\}@et.aau.dk)

Received: March 13, 2015; Accepted: September 15, 2015 begining and then switch to the backup sensor or execute proper system reconfiguration and fault tolerant control. Thus the fast and accurate fault diagnosis of the position sensor is essential to ensure the reliability as well as sensor fault tolerant operation of the SRWG.

Reference [14] proposed a square wave position edge prediction method for the position signal fault diagnosis and position faults recovery of SRM. However, the position sensor system investigated in this paper is three optical encoders based measurement system, which may limit the application scope of this approach. Despite few investigations on position sensor FDD, the rotor position estimation of SRM from which the sensor health status can be inferred has been studied a lot [15-28]. One possible solution for position sensor FDD in SRM which is widely used in control theory community is to extract and analyze the residual between the actual output and the estimated output if this estimated value is accurate enough [29]. Flux-current characteristics method, which is first proposed in [18], is the most popular method for rotor position estimation in medium and high speed operation of SRM. Flux linkage-current-angle relationship data is stored in a 2D lookup table which is used to estimate the rotor angle. The drawback of this method lies in occupation of mass software and hardware resources as well as long computing time due to table searching and interpolation processing. In order to overcome these shortcomings, plenty of nonlinear approximation solutions have been developed in the last decades based on the basic idea of flux linkage-currentangle characteristics of SRM. These solutions include fuzzy logic [17-21], Back-Propagation (BP) neural networks, Radial Basis Function (RBF) neural networks, 
adaptive neuro-fuzzy inference system [22-25]. The above methods substitute fuzzy or neural network models for the 2D lookup tables, which may release large amount of memory. However, the fuzzy logic rules in the fuzzy logic model are massive and require experience to create, meanwhile, most artificial neural networks models are based on iterative learning algorithm which is time consuming and hard to achieve global optimum.

This paper presents a fault diagnostic approach for position sensor in SRWG based on the residual between the actual output of the position sensor and the estimated rotor position which is obtained from an assembled estimator. Section 2 gives the position sensor fault pattern analysis of the SRWG. Section 3 presents the procedure of magnetization characteristics acquisition via FEA. The rotor position estimation of SRWG based on Extreme Learning Machine (ELM) is proposed in section 4. Section 5 illustrates the fault diagnostic approach for position sensor in SRWG based on analysis of the residual. The performance of the proposed approach is verified under various operating conditions and sensor fault scenarios. Section 6 presents the conclusion of this paper.

\section{Position Sensor Fault Pattern Analysis of SRWG}

\subsection{Position sensor of SRWG}

Accurate rotor position information is indispensable for the SRWG to determine the conducting phase / phases and turn-on / turn-off angles to achieve desired control performance. A typical wind power generation system configuration with SRG is depicted in Fig. 1, the position sensor measures the position angle of high speed shaft of the gearbox and feedbacks this signal to the controller of the asymmetric half bridge converter. The commonly used position sensors are optical encoders, hall-effect sensors and magnetic resolvers [14, 30].

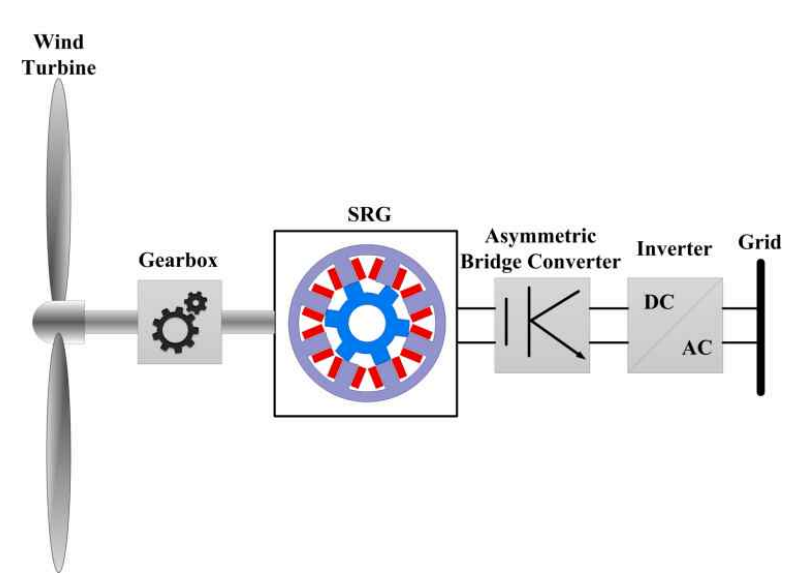

Fig. 1. A typical wind power generation system configuration with switched reluctance generator

\subsection{Position sensor fault analysis}

Owning to the harsh environments most Wind Energy Conversion Systems (WECS) usually work in, especially for offshore occasions, the mechanical position sensors are fragile under long-time extreme temperature, high humidity and salt mist conditions. In dusty environment, the optical encoders tend to be affected and may lose signals, while the hall-effect sensors are more susceptible to temperature.

Moreover, the magnetic resolvers are quite easily disturbed by electromagnetic radiation which is abundant in the nacelle of WECS. I $\mathrm{n}$ addition, the transmission channel, the power source and the related modulation and measurement circuits of the position signal may also be intervened by the external electromagnetic sources.

Thus the above mentioned factors may eventually result in intermittent or permanent faults in the software or hardware of the rotor position sensing systems. The false signals from the faulty rotor position sensor may affect the normal function of the feedback loop and the control system of the WECS. The incipient sensor fault could influence the power generation capacity of the WECS,

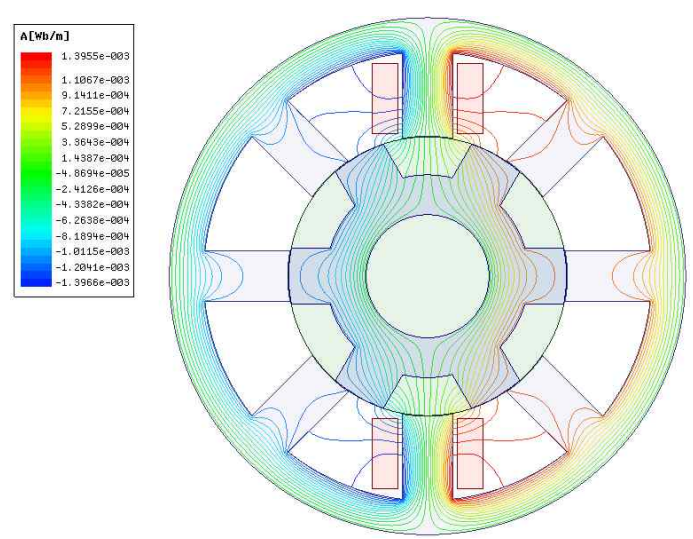

(a)

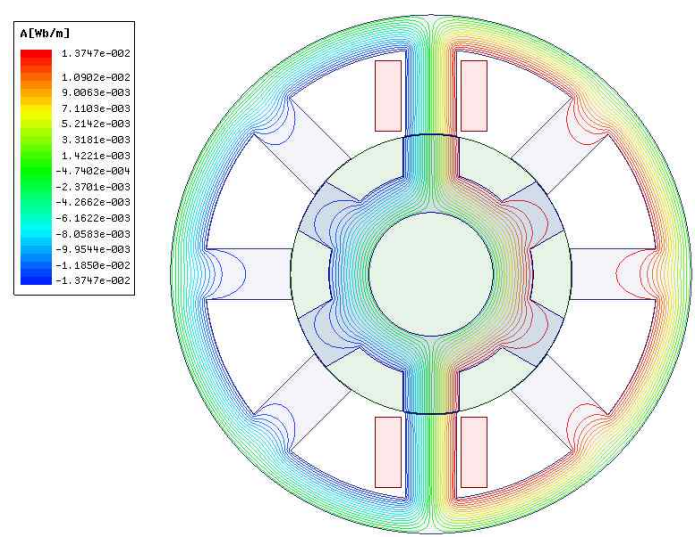

(b)

Fig. 2. Flux line distribution at different positions: (a) fully unaligned position; (b) fully aligned position 


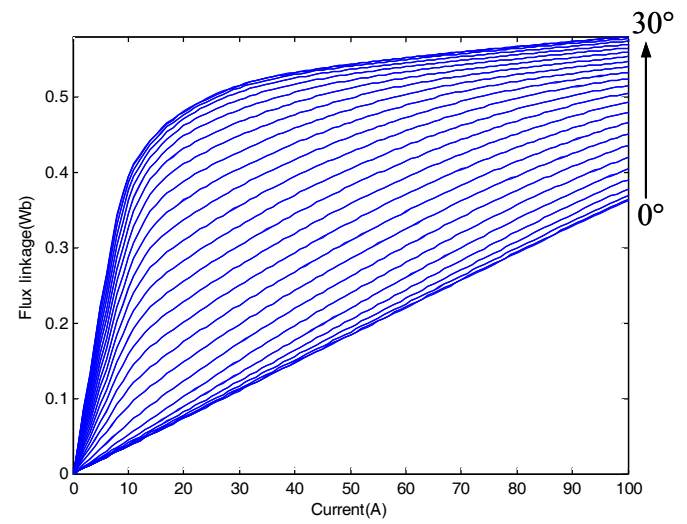

Fig. 3. The magnetic curve clusters of the studied SRWG

while more serious sensor faults may lead to catastrophic failures of the WECS.

\section{Magnetization Characteristics Acquisition via FEM}

Magnetization characteristics, which demonstrate the relationship among flux linkage, phase current and rotor position, is the foundation for rotor position estimation. 2D finite element model of a $7.5 \mathrm{kw} 8 / 6$ poles four-phase SRWG is developed using ANSYS MAXWELL to obtain the magnetization characteristics.

The fully unaligned position is defined as $0^{\circ}$, while the fully aligned position is $30^{\circ}$. The distributions of the flux line at the fully unaligned and aligned positions are shown in Fig. 2. Fig. 3 displays the magnetic curve clusters of phase A with an interval of $1.2^{\circ}$ in rotor position. As can be seen in Fig. 3, the flux linkage rises monotonically with the increase of phase current at each position. When the phase current reaches to certain extent, the variation tendency of the flux linkage is becoming unapparent owning to the flux saturation. At each fixed phase current, the flux linkage increases while the rotor position rotates from the fully unaligned position $\left(0^{\circ}\right)$ to aligned position $\left(30^{\circ}\right)$. Near the fully aligned position, the relationship between flux linkage and phase current is nonlinear. On the other hand, there is a nearly linear relationship between flux linkage and phase current near the fully unaligned position.

\section{Rotor Position Estimation of SRWG Based on ELM}

\subsection{Extreme learning machine}

Single hidden layer feedforward neural networks (SLFNs) which have universal approximation ability are widely used in state estimation of electrical machines.
Traditional parameter optimization of the SLFNs is based on iterative methods. Gradient descend methods, such as the most commonly used BP algorithm, are used to guide the learning process of parameters tuning iteratively with the training data. These methods are usually timeconsuming and hard to get the global optimal solutions. ELM is a recently developed novel learning algorithm for training the SLFNs [31-33]. The name 'ELM' also refers to the SLFNs trained by this algorithm. Thus in the following parts of this paper, ELM may be either of the two meanings. The only preset parameter of ELM is the number of hidden layer neurons. There is no need to tune the weights and threshold parameters in the learning process of ELM algorithm, and the unique optimal parameters can be obtained analytically via simple matrix computations. Hence it offers significant superiorities in terms of fast training speed, easy to implement, good generalization ability as well as minimal human involvement.

ELM has been used in power system applications to solve the prediction and state evaluation problems [34-35]. The key principle of ELM for rotor position estimation of SRWG is given as follows.

Suppose $\left\{\boldsymbol{x}_{i}, \boldsymbol{y}_{i}\right\}_{i=1}^{N}$ is $n$ sample dataset of a nonlinear system, where $\boldsymbol{x}_{i} \in \boldsymbol{R}^{n}$ with $\boldsymbol{x}_{i}=\left[x_{i 1}, x_{i 2}, \ldots, x_{i n}\right]^{T}, \boldsymbol{y}_{i} \in \boldsymbol{R}^{m}$ with $\boldsymbol{y}_{i}=\left[y_{i 1}, y_{i 2}, \ldots, y_{i m}\right]^{T}, n, m$ is the dimension of $\boldsymbol{x}_{i}$, $\boldsymbol{y}_{i}$, respectively. The goal is to approximate a model in the form of,

$$
f\left(\boldsymbol{x}_{j}\right)=\sum_{i=1}^{K} \boldsymbol{\beta}_{i} g\left(\boldsymbol{\omega}_{i} \cdot \boldsymbol{x}_{j}+b_{i}\right), j=1, \ldots, N
$$

where $\boldsymbol{\omega}_{i}=\left[\omega_{i 1}, \omega_{i 2} \ldots, \omega_{i n}\right]^{T}$ is the weight vector connecting the $i$ th hidden neuron and the input neurons, $\boldsymbol{\beta}_{i}=\left[\beta_{i 1}, \beta_{i 2} \ldots, \beta_{i n}\right]^{T}$ is the weight vector connecting the $i$ th hidden neuron and the output neurons, $b_{i}$ is the threshold of the $i$ th hidden neuron, $g(x)$ is the activation function, $K$ is the number of hidden neurons of ELM.

The ELM can approximate these $N$ samples with zero error means that $\sum_{j=1}^{K} f\left(\boldsymbol{x}_{j}\right)-\boldsymbol{y}_{j}=0$,

$$
\sum_{i=1}^{K} \boldsymbol{\beta}_{i} g\left(\boldsymbol{\omega}_{i} \cdot \boldsymbol{x}_{j}+b_{i}\right)=\boldsymbol{y}_{j}, j=1, \ldots, N
$$

The above equations can be rewritten in a compact form,

$$
\boldsymbol{G} \boldsymbol{\beta}=\boldsymbol{Y}
$$

where 


$$
\begin{gathered}
\boldsymbol{G}=\left[\begin{array}{ccc}
g\left(\boldsymbol{\omega}_{1} \cdot \boldsymbol{x}_{1}+b_{1}\right) & \cdots & g\left(\boldsymbol{\omega}_{K} \cdot \boldsymbol{x}_{1}+b_{K}\right) \\
\vdots & \ddots & \vdots \\
g\left(\boldsymbol{\omega}_{1} \cdot \boldsymbol{x}_{N}+b_{1}\right) & \cdots & g\left(\boldsymbol{\omega}_{K} \cdot \boldsymbol{x}_{N}+b_{K}\right)
\end{array}\right]_{N \times K} \\
\boldsymbol{\beta}=\left[\begin{array}{lll}
\boldsymbol{\beta}_{1} & \cdots & \boldsymbol{\beta}_{K}
\end{array}\right]^{\boldsymbol{T}} \\
\boldsymbol{Y}=\left[\begin{array}{lll}
\boldsymbol{y}_{1} & \cdots & \boldsymbol{y}_{K}
\end{array}\right]^{\boldsymbol{T}}
\end{gathered}
$$

here $\boldsymbol{G}$ is the hidden-layer output matrix of the SLFN, while $\boldsymbol{\beta}$ is the output weight matrix, $\boldsymbol{Y}$ is the target matrix.

The smallest norm least squares solution of the above regression system is

$$
\hat{\boldsymbol{\beta}}=\boldsymbol{G}^{\dagger} \boldsymbol{Y}
$$

where $\boldsymbol{G}^{\dagger}$ is the Moore-Penrose generalized inverse of matrix $\boldsymbol{G}$. The $\boldsymbol{G}^{\dagger}$ can be obtained via Singular Value Decomposition (SVD).

Thus the estimated output of the regression system $f\left(\boldsymbol{x}_{j}\right)$ can be expressed as,

$$
\boldsymbol{F}=\boldsymbol{G} \hat{\boldsymbol{\beta}}=\boldsymbol{G} \boldsymbol{G}^{\dagger} \boldsymbol{Y}
$$

The Mean Square Error (MSE) of the regression system is,

$$
\boldsymbol{e}^{2}=\frac{1}{N} \boldsymbol{F}-\boldsymbol{Y}^{2}=\frac{1}{N} \boldsymbol{G} \boldsymbol{G}^{\dagger} \boldsymbol{Y}-\boldsymbol{Y}^{2}
$$

\subsection{Rotor position estimation of SRWG}

The voltages and currents of the four phase windings will be delivered to a flux linkage calculator to calculate the flux linkage of each phase. If the leakage inductance between the phases is neglected, the flux linkage of the phase $k$ can be calculated by,

$$
\psi_{k}(t)=\int_{0}^{t}\left(u_{k}-R_{k} i_{k}\right) d t+\psi_{k}(0), k=1,2, \ldots, 4
$$

where $u_{k}, R_{k}, i_{k}$ are the phase voltage, phase resistance and phase current respectively. Then the current and flux linkage will be input to the corresponding ELM position estimator. There are four ELM estimators, each of which works in its own best estimation region. This will be introduced in detail in the next section.

Offline training and online estimation strategy, which may improve the efficiency of the ELM, is used in this study. After the training process, all the weights and biases parameters of the ELM rotor position estimator are determined. These parameters are configured into the online ELMs for real time rotor position estimation.

\section{Position Sensor Fault Diagnosis and Results Analysis}

\subsection{Simulation}

The configuration of the studied $7.5 \mathrm{kw} 8 / 6$ poles fourphase SRWG system is demonstrated in Fig. 4. The current chopping control strategy is deployed in the simulation for the current control, the hysteresis band width is $\pm 3 \mathrm{~A}$. The DC exciting voltage is $120 \mathrm{~V}$. Due to the generating mode of SRM, the turn-on and turn-off angles are set to be $30^{\circ}$ and $60^{\circ}$. The nominal rotor speed is $1000 \mathrm{rpm}$ while the nominal wind speed is $12 \mathrm{~m} / \mathrm{s}$. The simulation is implemented in Matlab/Simulink ${ }^{\circledR}$ environment. Each phase is working on the current chopping mode with the reference current $62.5 \mathrm{~A}$ and the hysteresis band width $\pm 3 \mathrm{~A}$. Adjacent phases have a phase shift of $15^{\circ}$.The optimal rotor speed of the SRWG is determined by referring to the wind speed to extract the maximum power from the wind [36], which is shown in Fig. 4.

1299 samples are collected from the flux linkagecurrent-angle relationship. The input weights and bias are generated randomly, the output weights are analytically calculated using the extremely fast ELM. It takes only 0.8292 s to learn the 1299 samples, which is almost impossible for other iterative algorithms given the same hardware conditions. The ELM estimator only works in the range of $30^{\circ}$ which is restricted to the magnetic

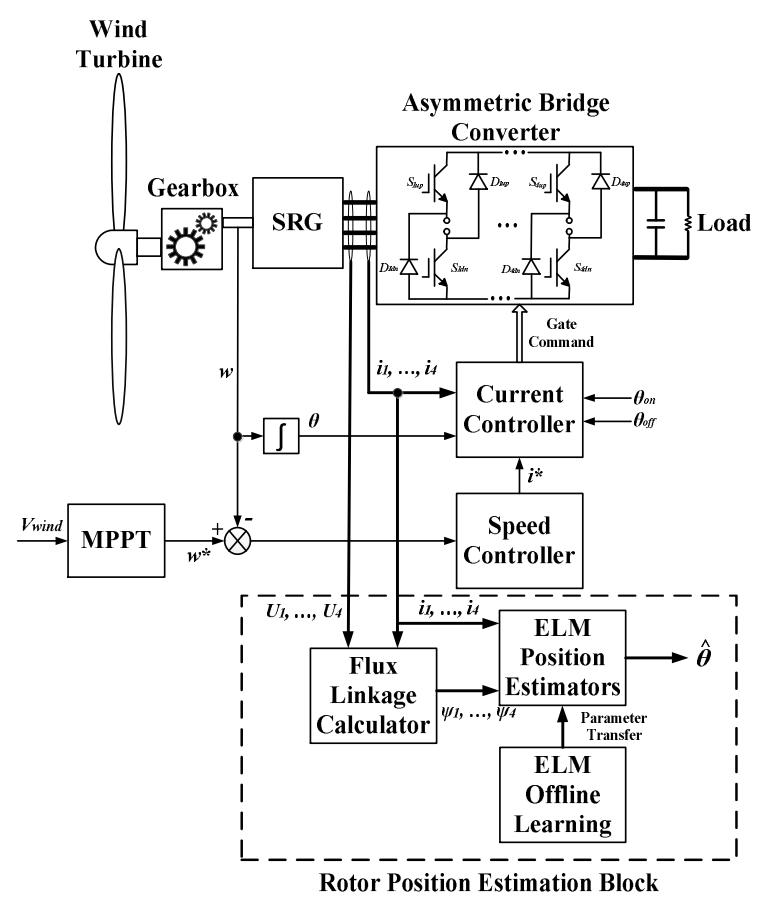

Fig. 4. Configuration of the SRWG system and the rotor position estimation module 


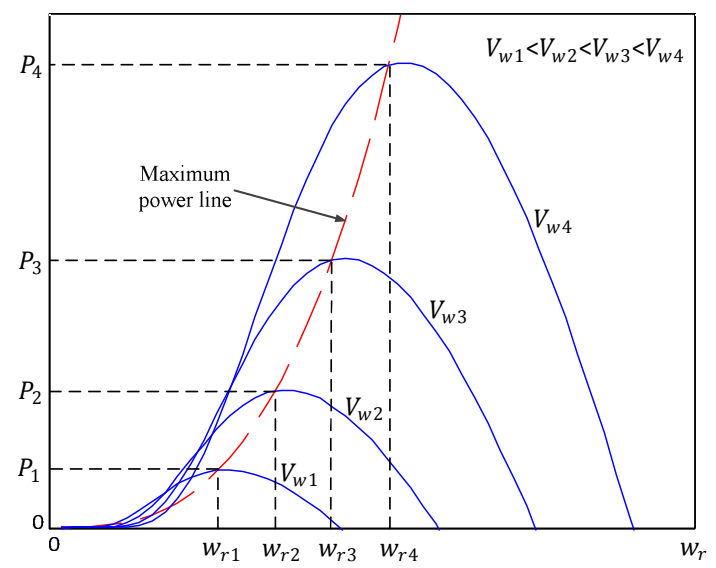

Fig. 5. Maximum power point tracking

characteristics. Thus, when the current and flux linkage of certain phase are nonzero, they could be used by the ELM to estimate a $30^{\circ}$ range of the rotor angle.

Three types of sensor faults are simulated in this study to verify the effectiveness of the proposed diagnosis method. The faults include bias fault, drifting fault and intermittent fault. The bias fault is simulated by adding a constant shift to the output of the position sensor. A monotone increase is superimposed to the sensing signal to simulate the drifting fault. For the intermittent fault, a narrow bandwidth long flat-top pulse is imposed on the sensor's output.

\subsection{Rotor position estimation}

The estimation results of the four separate ELMs when the wind speed is $12 \mathrm{~m} / \mathrm{s}$ and the generator speed is 1000 rpm are show in Fig. 6. Theoretically, only two phases with $30^{\circ}$ phase shift (such as phase $\mathrm{C}$ and $\mathrm{A}$ ) is enough to estimate the whole $60^{\circ}$ angle cycle. However, as can be seen in Fig. 7, the estimation results are undesirable, which is due to the nonlinear magnetization characteristics of the SRWG. As shown in Fig. 3, the magnetic curves near the aligned, unaligned as well as low current regions are crowded together or even intersecting, which may reduce the accuracy of such advanced estimation algorithms. For the intersection points in the magnetic curves, it is a challenging task to estimate the rotor position precisely only using flux linkage-current-angle relationship because of the non-unique mapping. In fact, there is a distinguished region among the aligned, unaligned and the certain current and flux linkage range for rotor position estimation, which results in the relatively accurate estimation range of about $20^{\circ}$ shown in Fig. 6 . Therefore, $15^{\circ}$ sensitive region of each ELM is selected to contribute the whole $60^{\circ}$ range angle estimation. The improved results are demonstrated in Fig. 7. The estimated rotor angle is very close to the real rotor position as shown in Fig. 7. The detailed estimation results under various operating conditions are presented in the following section.

The assembled ELM estimation results under different

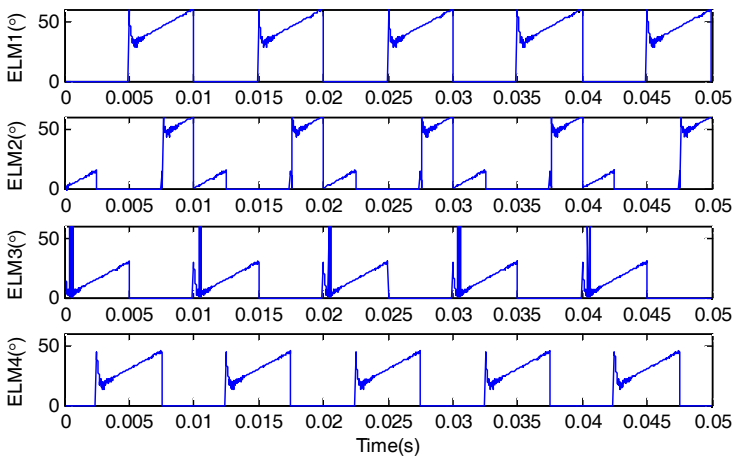

Fig. 6. Outputs of ELM estimators
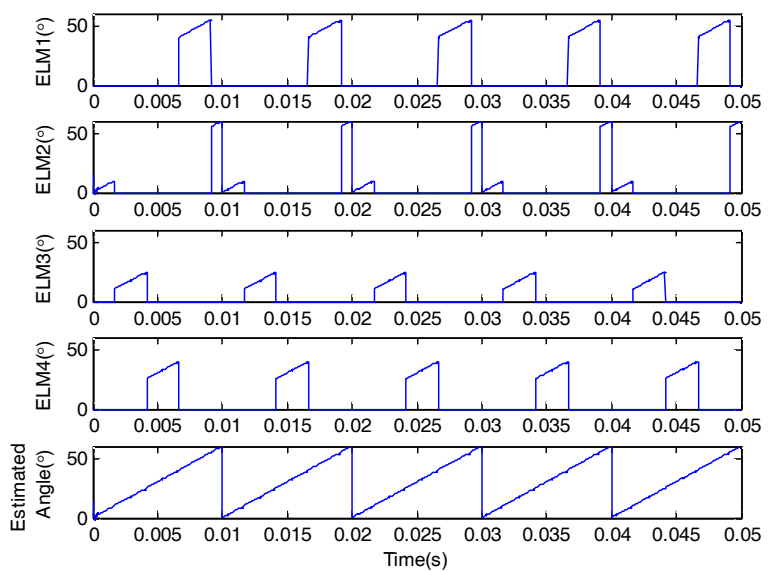

Fig. 7. Outputs of the improved assembled ELM estimators and estimated rotor angle

Table 1. The ELM estimation error at different operating conditions

\begin{tabular}{c|c|c|c}
\hline \multirow{2}{*}{} & \multicolumn{3}{|c}{ Operating Condition (wind speed, $\mathrm{m} / \mathrm{s})$} \\
\cline { 2 - 4 } & $\begin{array}{c}8 \\
(667 \mathrm{rpm})\end{array}$ & $\begin{array}{c}12 \\
(1000 \mathrm{rpm})\end{array}$ & $\begin{array}{c}6-12 \\
(500-1000 \mathrm{rpm})\end{array}$ \\
\hline $\operatorname{MAE}\left(^{\circ}\right)$ & 0.7273 & 0.5748 & 2.3633 \\
\hline RMSE $\left(^{\circ}\right)$ & 0.1949 & 0.1617 & 0.2870 \\
\hline
\end{tabular}

operating conditions are shown in Fig. 8, Fig. 9 and Fig. 10, respectively.

In the case of $12 \mathrm{~m} / \mathrm{s}$ wind speed, the generator speed is $1000 \mathrm{rpm}$. As shown in Fig. 7(b), the Maximum Absolute Error (MAE) of ELM estimation is $0.5748^{\circ}$, the Root Mean Squared Error (RMSE) is $0.1617^{\circ}$. The MAE and RMSE are both higher with $8 \mathrm{~m} / \mathrm{s}$ wind speed. As the wind speed increases linearly from 6 to $12 \mathrm{~m} / \mathrm{s}$, the generator speed increases from 500 to $1000 \mathrm{rpm}$, the estimation error is bigger at the low speed stage. The MAE and RMSE results are presented in Table 1. Although the MAE in the 500 to $1000 \mathrm{rpm}$ acceleration operating condition is relatively larger, the RMSEs are very low (no greater than $0.3^{\circ}$ ) in all the three operation conditions which indicate the overall estimation performance of the proposed method is satisfying.

It is noted that the MAEs in the cases of $8 \mathrm{~m} / \mathrm{s}$ wind 

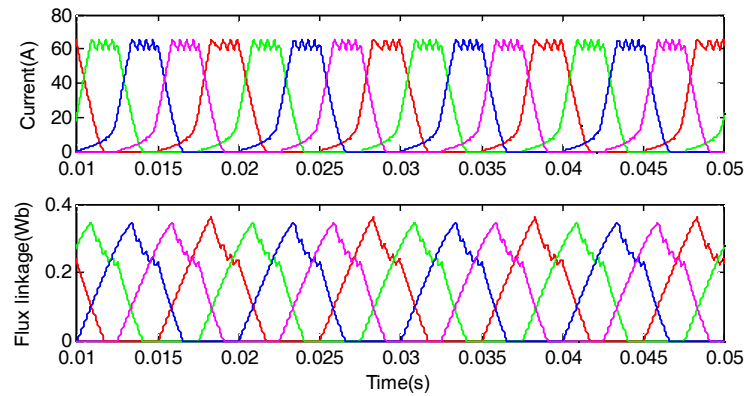

(a)
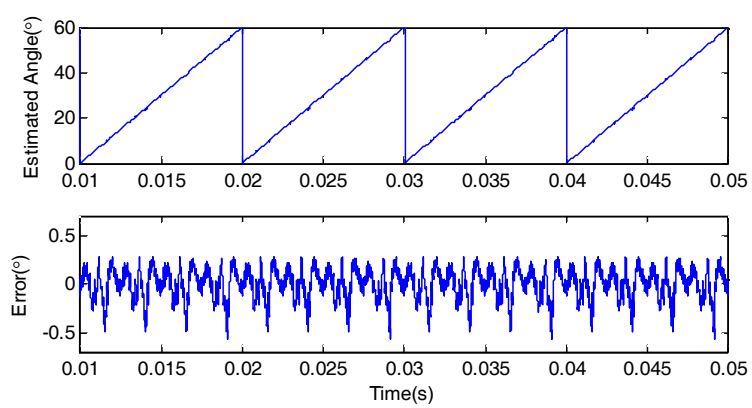

(b)

Fig. 8. Assembled ELM estimation result when wind speed is $12 \mathrm{~m} / \mathrm{s} \quad\left(w_{r}=1000\right) \mathrm{rpm}$, (a) current and flux linkage waveforms, (b) estimation result
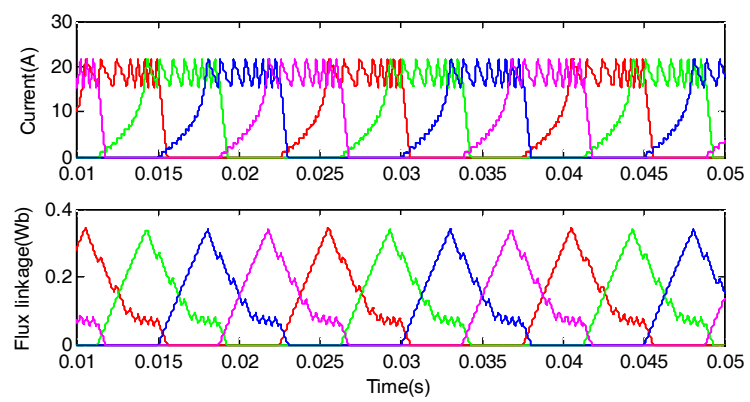

(a)
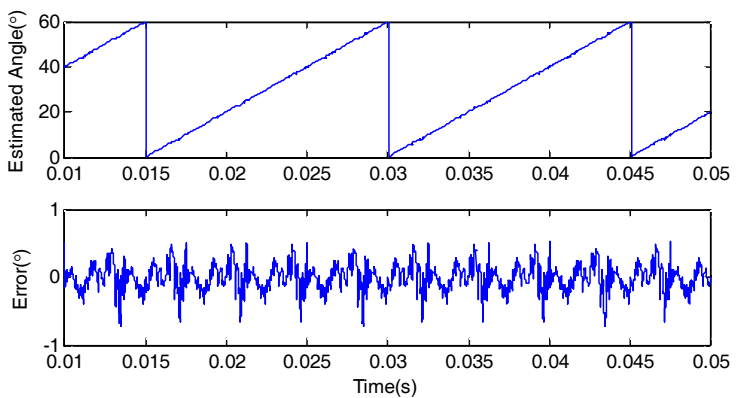

(b)

Fig. 9. Assembled ELM estimation result when wind speed is $8 \mathrm{~m} / \mathrm{s}\left(w_{r}=667\right) \mathrm{rpm}$, (a) current and flux linkage waveforms, (b) estimation result

speed and $12 \mathrm{~m} / \mathrm{s}$ wind speed conditions always appear when the corresponding current and flux linkage are in the transitional area between the distinguished and crowded
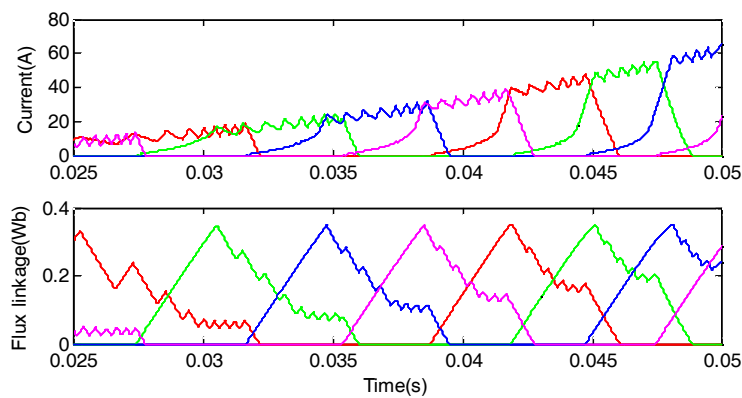

(a)
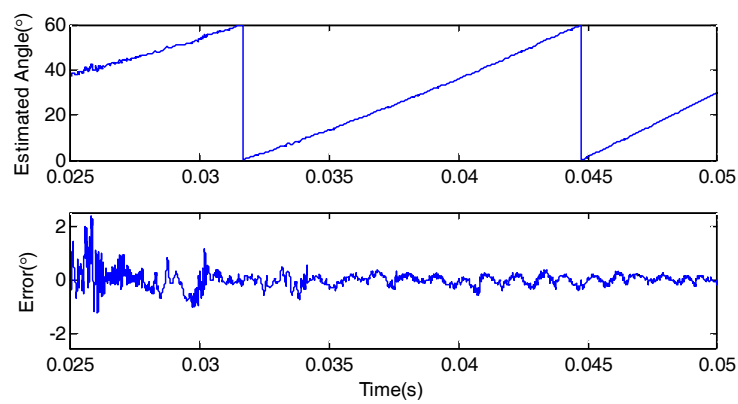

(b)

Fig. 10. Assembled ELM estimation result when wind speed from $6 \mathrm{~m} / \mathrm{s}$ to $12 \mathrm{~m} / \mathrm{s}, w_{r}$ from 500 to 1000 rpm, (a) current and flux linkage waveforms, (b) estimation result

regions of the magnetization characteristic curve, which may affect the performance of the ELM estimators. However, $0.7273^{\circ}$ and $0.5748^{\circ}$ of MAE are satisfying for position estimation. For the wind speed increasing from 6 to $12 \mathrm{~m} / \mathrm{s}$ operating condition, the MAE is $2.3633^{\circ}$, the relative large errors are all appear before reaching $700 \mathrm{rpm}$ $(0.035 \mathrm{~s})$.

The corresponding current and flux linkage in this case are in the crowded region of the magnetization characteristic curve which is inevitable in this operation condition.

\subsection{Result analysis of sensor fault diagnosis}

The residual generated under normal sensor condition when wind speed varies from $6 \mathrm{~m} / \mathrm{s}$ to $12 \mathrm{~m} / \mathrm{s}$ is shown in Fig. 11. The residual generated under the bias fault, drifting fault and intermittent are demonstrated in Fig. 12, 13, and 14 , respectively. Since the MAE is $2.3633^{\circ}$ in this variable speed operating condition which is shown in Table 1 , the threshold to determine the normal/abnormal status of the sensor is set to be $\pm 2.5^{\circ}$. As can be seen in Fig. 11, the residual from $0.03 \mathrm{~s}$ to $0.05 \mathrm{~s}$ when the sensor is healthy and the wind speed is variable has little variations which are all within the threshold range.

As shown in Fig. 12, the bias fault occurs at $0.04 \mathrm{~s}$ and lasts until $0.05 \mathrm{~s}$, the generated residual has a rapid rise and exceeds the set upper threshold of $2.5^{\circ}$ quickly just after the occurrence of this sensor fault. It is observed that the 


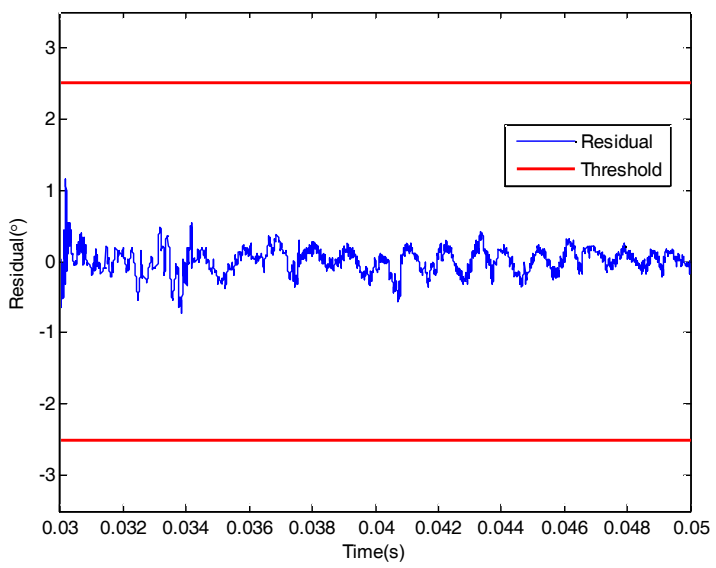

Fig. 11. Residual under normal sensor condition when wind speed from $6 \mathrm{~m} / \mathrm{s}$ to $12 \mathrm{~m} / \mathrm{s}$

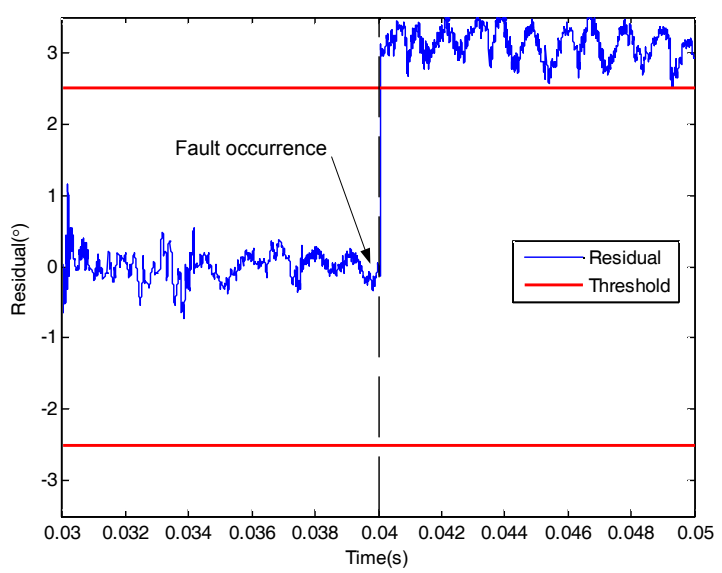

Fig. 12. Residual under sensor bias fault condition when wind speed from $6 \mathrm{~m} / \mathrm{s}$ to $12 \mathrm{~m} / \mathrm{s}$

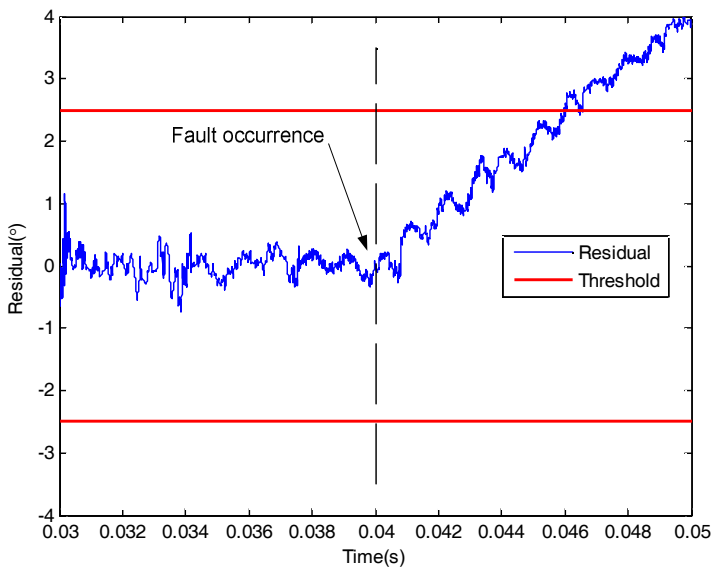

Fig. 13. Residual under sensor drifting fault condition when wind speed from $6 \mathrm{~m} / \mathrm{s}$ to $12 \mathrm{~m} / \mathrm{s}$

average residual fluctuation also has a slight increase compared with the normal case.

Fig. 13 presents the residual curve under sensor drifting fault condition when wind speed from $6 \mathrm{~m} / \mathrm{s}$ to $12 \mathrm{~m} / \mathrm{s}$. The

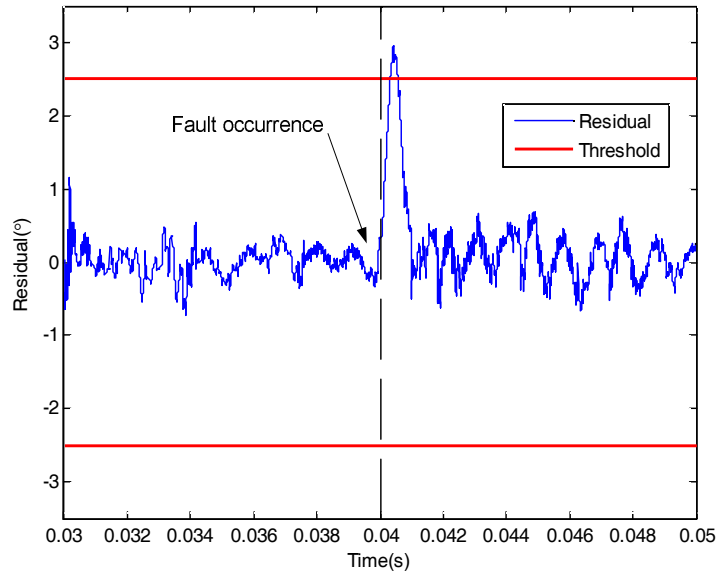

Fig. 14. Residual under sensor intermittent fault condition when wind speed from $6 \mathrm{~m} / \mathrm{s}$ to $12 \mathrm{~m} / \mathrm{s}$

residual in the drifting fault occasion keeps gentle increase between $0.03 \mathrm{~s}$ and $0.05 \mathrm{~s}$. The fault residual reaches and passes the upper threshold at about $0.046 \mathrm{~s}$. The fault alarm can be triggered at around $0.047 \mathrm{~s}$ dependent on the setting.

As is demonstrated in Fig. 14, a peak pulse of the residual is produced between $0.04 \mathrm{~s}$ and $0.041 \mathrm{~s}$ in the intermittent sensor fault circumstance when wind speed from $6 \mathrm{~m} / \mathrm{s}$ to $12 \mathrm{~m} / \mathrm{s}$. It is noted that the average residual fluctuation also has an increase compared with the normal case.

To summarize, when the rotor position sensor has a fault, the output of the sensor can't represents the real rotor position while the proposed assembled ELM estimator can still estimate the rotor position with high accuracy, which generates an abrupt change of the residual. Once the residual exceeds the set threshold, the fault alarm can be triggered which indicates the detection of fault. By analyzing the generated residuals, different kinds of rotor position fault are identified. According to the simulation and results analysis, the common faults such as bias fault, drifting fault and intermittent fault have been detected and diagnosed accurately by using the proposed position sensor fault diagnostic scheme.

\section{Conclusion}

This paper presents a novel rotor position sensor fault diagnostic scheme for SRWG based on assembled ELM. Simulation results show that the learning speed of ELM is extremely fast, the rotor position estimation accuracy is also very high with the best RMSE of $0.1617^{\circ}$. The sensor faults including bias fault, drifting fault and intermittent fault have been detected and diagnosed accurately by using the proposed position sensor fault diagnostic approach. The rotor position estimation method as well as sensor fault diagnostic scheme proposed in this paper are of great significance for cost reduction, reliability improvement and 
predictive maintenance of SRWG. The proposed method is promising in the application of virtual sensor, position sensor redundancy, sensor-less control and sensor fault tolerant control of SRWG.

\section{Acknowledgements}

This work was partially supported by Danish Agency for Science, Technology and Innovation, under "Research on DC Network Connection with A Novel Wind Power Generator System," DSF-10-094560, and China Scholarship Council.

\section{References}

[1] D. A. Torrey, "Variable-reluctance generators in wind-energy systems," in Proc. IEEE PESC'93, 1993, pp. 561-567.

[2] R. Cardenas, W. F. Ray, and G. M. Asher, "Switched reluctance generators for wind energy applications," in Proc. IEEE PESC'95, 1995, pp. 559-564.

[3] K. Park and Z. Chen, "Self-tuning fuzzy logic control of a switched reluctance generator for wind energy applications," in Proc. IEEE 3rd Int. Symp. Power Electron. Distrib. Gener. Syst., 2012, pp. 357-363.

[4] R. Cardenas, R. Pena, M. Perez, J. Clare, G. Asher, and P. Wheeler, "Control of a switched reluctance generator for variable-speed wind energy applications," IEEE Trans. Energy Convers., vol. 20, no. 4, pp. 781-791, Dec. 2005.

[5] E. Echenique, J. Dixon, R. Cardenas, and R. Pena, "Sensorless control for a switched reluctance wind generator, based on current slopes and neural networks," IEEE Trans. Ind. Electron., vol. 56, no. 3, pp. 817-825, Mar. 2009.

[6] S. Mendez, A. Martinez, W. Millan, C. E. Montano, and F. Perez-Cebolla, "Design, Characterization, and Validation of a 1-kW AC Self-Excited Switched Reluctance Generator," IEEE Trans. Ind. Electron., vol. 61, no. 2, pp. 846-855, Feb. 2014.

[7] D. A. Torrey, "Switched reluctance generators and their control," IEEE Trans. Ind. Electron., vol. 49, no. 1, pp. 3-14, Feb. 2002.

[8] X. Liu, K. Park and Z. Chen, "A Novel Excitation Assistance Switched Reluctance Wind Power Generator," IEEE Trans. on Magn., vol. 50, no. 11, pp. 1-4, Nov. 2014.

[9] H. Chen and S. Lu, "Fault diagnosis digital method for power transistors in power converters of switched reluctance motors," IEEE Trans. Ind. Electron., vol. 60, no. 2, pp. 749-763, 2013.

[10] S. Gopalakrishnan, A. M. Omekanda, and B. Lequesne, "Classification and Remediation of Electrical Faults in the Switched Reluctance Drive",
IEEE Trans. Ind. Appl., vol. 42, no. 2, 2006, pp.479486.

[11] B. Schinnerl and D. Gerling, "Analysis of winding failure of switched reluctance motors," in Proc. IEEE IEMDC'09, 2009, pp. 738-743.

[12] J. F. Marques, J. O. Estima, N. S. Gameiro, and A. J. M. Cardoso, "A New Diagnostic Technique for RealTime Diagnosis of Power Converter Faults in Switched Reluctance Motor Drives," IEEE Trans. Ind. Appl., vol. 50, no. 3, pp. 1854-1860, May./Jun. 2014.

[13] H. Torkaman and E. Afjei, "Comprehensive detection of eccentricity fault in switched reluctance machines using high frequency pulse injection," IEEE Trans. Power Electron., vol. 28, no. 3, pp.1382 -1390, 2013.

[14] J. Cai, Z. Q. Deng, and R. G. Hu, "Position Signal Faults Diagnosis and Control for Switched Reluctance Motor," IEEE Trans. Magn., vol. 50, no. 9 , 2014.

[15] M. Ehsani and B. Fahimi, "Elimination of position sensors in switched reluctance motor drives: State of the art and future trends," IEEE Trans. Ind. Eletron., vol. 49, no. 1, pp. 40-47, Feb. 2002.

[16] I. H. Al-Bahadly, "Examination of a sensorless rotor position measurement method for switched reluctance drive", IEEE Trans. Ind. Eletron., vol. 55, no. 1, pp. 288-295, 2008.

[17] L. Xu and C. Wang, "Accurate rotor position detection and sensorless control of SRM for super-high speed operation," IEEE Trans. Power Electron., vol. 17, no. 5, pp. 757-763, 2002.

[18] J. P. Lyons, S. R. MacMinn, and M. A. Preston, "Flux-current methods for SRM rotor position estimation," in Proc. Conf. Rec. IEEE-IAS Annu. Meeting, 1991, pp. 482-487.

[19] A. D. Cheok and N. Ertugrul, "High robustness and reliability of fuzzy logic based position estimation for sensorless switched reluctance motor drives," IEEE Trans. Power Electron., vol. 15, no. 2, pp. 319334, 2000.

[20] A. D. Cheok and Z. F. Wang, "Fuzzy logic rotor position estimation based switched reluctance motor DSP drive with accuracy enhancement," IEEE Trans. Power Electron., vol. 20, no. 4, pp. 908-921, 2005.

[21] N. Ertugrul and A. D. Cheok, "Indirect angle estimation in switched reluctance motor drive using fuzzy logic based motor model," IEEE Trans. Power Electron., vol. 15, no. 6, pp. 1029-1044, 2000.

[22] A. D. Cheok and N. Ertugrul, "Use of fuzzy logic for modeling, estimation, and prediction in switched reluctance motor drives," IEEE Trans. Ind. Electron., vol. 46, no. 6, pp. 1207-1224, 2000.

[23] A. D. Cheok and N. Ertugrul, "High robustness of an SR motor angle estimation algorithm using fuzzy predictive filters and heuristic knowledge-based rules," IEEE Trans. Ind. Electron., vol. 46, no. 5, pp. 
904-916, 2000.

[24] E. Mese and D. A. Torrey, "An approach for sensorless position estimation for switched reluctance motors using artificial neural networks," IEEE Trans. Power Electron., vol. 17, no. 1, pp. 66-75, 2002.

[25] L. Henriques, L. Rolim, W. Suemitsu , J. Dente and P. Branco, "Development and experimental tests of a simple neuro-fuzzy learning sensorless approach for switched reluctance motors, "IEEE Trans. Power Electron., vol. 26, no. 11, pp. 3330-3344, 2011.

[26] S. Paramasivam, S. Vijayan, M. Vasudevan, R. Arumugam, and R. Krishnan, "Real-time verification of AI based rotor position estimation techniques for a 6/4 pole switched reluctance motor drive," IEEE Trans. Magn., vol. 43, no. 7, pp. 3209-3221, 2007.

[27] C. A. Hudson, N. S. Lobo, and R. Krishnan, "Sensorless control of single switch-based switched reluctance motor drive using neural network," IEEE Trans. Ind. Electron., vol. 55, no. 1, pp. 321-329, 2008.

[28] C. Wang, X. Liu, and Z. Chen, "Rotor Position Estimation for Switched Reluctance Wind Generator Using Extreme Learning Machine," Proc. of WEGAT 2014, 2014, pp. 1-8.

[29] R. Isermann, "Model-based fault-detection and diagnosis-Status and applications," Annu. Rev. Control, vol. 29, no. 1, pp.71-85, 2005.

[30] G. Scelba, G. De Donato, F. Bonaccorso, G. Scarcella, F. Giulii Capponi, "Fault Tolerant Rotor Position and Velocity Estimation Using Binary Hall-Effect Sensors for Low Cost Vector Control Drives," IEEE Trans. Ind. Appl., vol. 50, no. 5, pp. 3403-3413, Sept.-Oct. 2014.

[31] G. B. Huang, Q. Y. Zhu, and C. K. SiewK, "Extreme learning machine: Theory and applications," Neurocomputing, vol. 70, nos. 1-3, pp. 489-501, Dec. 2006.

[32] N. Y. Liang, G. B. Huang, P. Saratchandran, and N. Sundararajan, "A fast and accurate online sequential learning algorithm for feedforward networks," IEEE Trans. Neural Netw., vol. 17, no. 6, pp. 1411-1423, Nov. 2006.

[33] G. B. Huang, H. M. Zhou, X. J. Ding, and R. Zhang, "Extreme learning machine for regression and multiclass classification," IEEE Trans. Syst., Man, Cybern., B, Cybern., vol. 42, no. 2, pp. 513-529, Apr. 2012.

[34] C. Wan, Z. Xu; P. Pinson, Z. Y. Dong, and K. Wong, "Probabilistic Forecasting of Wind Power Generation Using Extreme Learning Machine", IEEE Trans. Power Syst., pp. 1033-1044, vol. 29, no. 3, May 2014

[35] A. H. Nizar, Z. Y. Dong, and Y. Wang, "Power utility nontechnical loss analysis with extreme learning machine method," IEEE Trans. Power Syst., vol. 23, no. 3, pp. 946-955, Aug. 2008.

[36] F. Deng and Z. Chen, "Power Control of Permanent Magnet Generator Based Variable Speed Wind Turbines," in Proc. ICEMS '09, 2009, pp. 1-6.

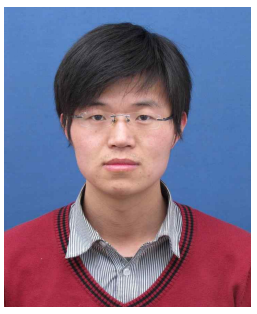

Chao Wang He received M.Sc. degree in Control Theory and Control Engineering from Zhejiang University, China in 2011. His research interest is fault diagnosis of wind turbines.

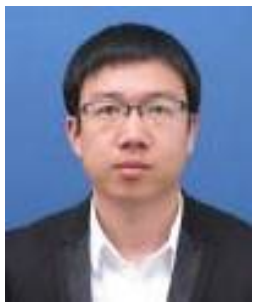

Xiao Liu He received $\mathrm{PhD}$ degree in Electrical Engineering from Zhejiang University, China, in 2008. He is currently an Assistant Professor with the Department of Energy Technology, Aalborg University, Denmark. His research interests are design, optimization and control of electrical machine and magnetic transmission.

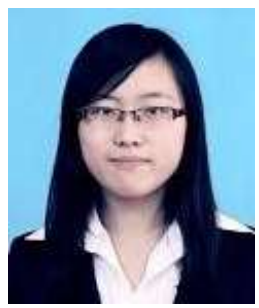

Hui Liu She received the M.Sc. degree in Electrical Engineering from Zhejiang University, Hangzhou, China, in 2012. She is currently working toward the Ph.D. degree in Aalborg University on power electronics.

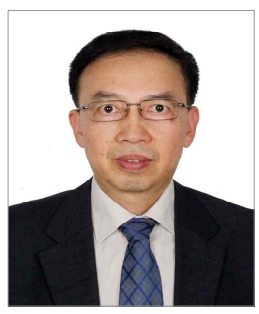

Zhe Chen He received $\mathrm{PhD}$ degree in Electrical Engineering from Durham University, UK. He is a full Professor with the Department of Energy Technology, Aalborg University, Aalborg, Denmark. He is the Leader of Wind Power System Research program at the Department of Energy Technology, Aalborg University, and the Danish Principle Investigator for Wind Energy of Sino-Danish Centre for Education and Research. He has led many research projects and has more than 360 publications in his technical field. His research interests are power systems, power electronics, and electric machines, and his main current research interests include wind energy and modern power systems. Dr. Chen is an Editor of the IEEE TRANSACTIONS ON POWER SYSTEMS, an Associate Editor (Renewable Energy) of the IEEE Transactions on Power Electronics, a Fellow of the Institution of Engineering and Technology (London, U.K.), and a Chartered Engineer in the U.K. 